\title{
RENEWABLE ENERGY, SUSTAINABILITY PARADOX AND THE POST-URBAN QUESTION
}

In his address to the Paris 2015 UN Conference on Climate Change (COP21 Summit), Indian Prime Minister Narendra Modi affirmed India's commitment to a sustainable path to prosperity, toning down the energy intensity of its growth through ambitious targets where

\begin{abstract}
by 2030 , we will reduce emissions by 33 to 35 per cent of 2005 levels, and 40 per cent of our installed capacity will be from our non-fossil fuels. We will achieve it by expanding renewable energy - for example, by adding 175 Gigawatts of renewable generation by 2022. We will enlarge our forest cover to absorb at least 2.5 billion tonnes worth of carbon dioxide. We are reducing dependence on fossil fuel through levies and reduction in subsidies switching sources of fuel where possible; and, transforming cities and public transportation.1
\end{abstract}

Over a short span of few years, India's vanguard position as a renewables leader has come to be hailed globally as it unfolds a formidable new energy legacy through a relentless pursuit of non-fossil alternatives, ranking $2^{\text {nd }}$ in the 'Renewables Energy Country Attractive Index 2017' (RECAI) with a fourth largest installed capacity of wind power, third largest concentrated solar power, and a forecast for more than doubling the share of renewables within its total energy capacity to 40 per cent. ${ }^{2}$ If India adheres to this plan, it will soon be the third largest renewable energy producer, behind China and the USA. As the world remains enthralled with India's 'spectacular achievements' in the realm of renewable energy, this marked shift comes after years of recalcitrance at COP summits where it was known for its reluctance in ratifying any binding agreement despite a considerable growth in its own Greenhouse Gas (GHG) emissions. ${ }^{3}$ Indian politicians have time and again built an argument around energy poverty and equity, resisting a blanket compliance with steps proposed at these

\footnotetext{
$1 \mathrm{https://www.narendramodi.in/speeches;} \mathrm{Speeches} \mathrm{made} \mathrm{on} \mathrm{25.09.2015} \mathrm{and} \mathrm{30.11.2015.}$

${ }^{2}$ RECAI is an indicator developed by the international accounting firm, Ernst \& Young determining a nation's attractiveness to renewable investments.

https://www.ey.com/gl/en/industries/power---utilities/renewable-energy-country-attractiveness-index

${ }^{3}$ Not all agree with this kind of hue and cry. Dubash et al (2018) take up the issue of whether India can be considered an emissions villain or hero. They examine a range of projected 2030 emissions (based on 2015 policies) to draw a more sympathetic conclusion that a doubling of India's energy-based CO2 emissions from 2012 levels can reasonably be considered an upper bound for 2030 emissions, reinforced by recent trends toward lower than expected electricity demand, a faster than expected transition from coal to renewables and a per capita emissions in 2030 that will remain well below today's global average.
} 
gatherings to tackle the concerns of a 'global environmental change', insisting instead on a more distinctive regional approach to global warming, one that emphatically drew the line between the responsibilities of the global North and the global South (Jasanoff 1993). Successive Indian governments have thus maintained an authoritative standing between committing the country to a standardized international obligation versus its own internal priorities where links between environment and development continue to be tenuously shaped. This remains the mainstay argument of the Indian state including the current Modi government for whom India's energy demand has been dominated by the highly publicized fact of 300 million people (mostly in rural households) without access to electricity.

Popular accounts are generally effusive about Modi's penchant for renewables, citing carefully circulated narratives about his earlier track record as Chief Minister of the western state of Gujarat transforming it supposedly into a model of sustainable development. Offering a more balanced and cautious overview of Modi's energy politics in his Wired article, American journalist and author Charles Mann (2015) acknowledged the examples cited to substantiate Modi's green agenda in Gujarat, including the transformation of the state capital city of Gandhi Nagar into a "solar city", creation of Asia's first Ministry of Climate, and a pioneering programme to install solar panels atop irrigation canals. The highlight was the commissioning of Asia's biggest solar park at Charanka Village, $350 \mathrm{~km}$ from the capital. Covering over 2000 ha, the park has attracted investment from different developers, with $600 \mathrm{MW}$ of installed capacity so far, is considered the world's second largest photovoltaic power station, and a model for solar parks all over India even though these energy landscapes reveal a controversial politics of land dispossession through the creation of new kinds of territories that are essentially bounded in localities and simultaneously globalized zones of capital, completion and speculation (McEwan 2017; McCarthy and Thatcher 2017; Yenneti et al. 2016).

As Mann (2015) reminds us, renewable energy is only a part of Modi's reformed energy regime where powering the nation through coal reserves is still dominant with nearly 60 per cent of total installed capacity and contributing to 75 per cent of overall electricity generation. A dedicated Ministry of Coal alongside public sector enterprises 
such as Coal India Limited (CIL) still play a significant role in India's resource nationalism (Lahiri-Dutt 2016, Chatterjee 2017). And, even though the government has relented on tapping further into India's vast coal reserves, announcing that no new plants will be constructed after 2022, reality is more muddled in what is a never ending see-saw, as reports released by different institutional authorities contradict each other vis-a-vis energy policies. ${ }^{4}$ With renewable energy selling at unit prices much lower than that of coal (nearly 30 per cent less) it might seem as if coal is not just a poor environmental proposition for the Indian state but a financial one as well. However, investing in renewables is equally dicey given the large number of private market players who are naturally concerned by this tariff freefall pushing them to bid at ever decreasing prices amidst a still evolving technology and other uncertainties (Swain and Sharma 2016).

Thus, as India's latest adventure with renewables cloaks itself with a string of superlatives, it is important to deliberate these next to impossible targets and question the state's supercilious claims of surpassing such goals in a record-breaking fashion. Consider, for instance, the government's landmark announcement in May 2018 of its electoral promise fulfillment, 100 per cent village electrification. This turned out to be a matter of interpretation as 31 million households or nearly 150 million villagers (i.e. 50 per cent) still remain without any electricity connection. What happened was a typical development scheme rush to meet a much-delayed deadline, where transformers were installed in each of the villages with a single power line connecting to the grid, making certain that at least 10 per cent of the households and all public facilities such as schools and health centres were connected. There was no reckoning of what kind of energy policy was deployed or any attempt in exploring the prospects of renewables in this particular effort, in what is clearly a missed opportunity.

It is in light of such political and policy disingenuity that we need to address "the lack of scientific certainty" inherent in the construction of facts (Latour 2004: 226).

\footnotetext{
4 For instance, the National Energy Policy 2017 drafted by NITI Aayog (National Institute for Transforming India, Government of India's think-tank that replaced its earlier long-serving Planning Commission) in its heavily growth focussed forecast considers coal investments in the longer term while the Draft National Electricity Plan 2016 prepared by India's Central Electricity Authority promised no new coal plants till 2027.
} 
Commencing at this point, the aim of this paper is to, first of all, attempt a more scrupulous reading of the hype of renewable energy that is being carefully orchestrated in India. The intention is to bypass the din and ensconce renewables within a critical energy discourse, interrogating its idea as well as its practice. A broad range of critical energy geographies scholarship (cf. Harrison and Popke 2017) have attempted a judicious evaluation of renewables in an effort to invest it with more analytical rigour, subjecting it to a critique at two levels: as an utopian-ideological project generating a particular kind of political discourse (energy nationalism and its ilk), as well as an appraisal of its embeddedness in green capitalism. ${ }^{5}$ Continuing this kind of scrutiny where 'the critical mind, if it is to renew itself and be relevant again, is to be found in....a realism dealing with....matters of concern, not matters of fact' (Latour 2004: 231), the first section attempts to disturb the entrenched idea of 'renewables as science' questioning the barrage of numbers employed in the fabrication of a specific energy fable. What might seem like a spin is actually a more systematic invocation of a calculative ethos emphasizing a temporal fix where an 'empirics of targets' are persuasively employed to gloss over the crucial distinction between the potential and the real. Metrics and measures are used authoritatively to generate a 'numericized space of public discourse' (Rose 1991: 675) where renewables are calibrated through criteria such as installed capacity and presented as an aggregate in a statistically significant manner. But, as the second part of the paper shows, despite their popularization through such a manipulation, by pegging it to a speculative value of market-based energy production, renewables unwittingly import assumptions of an existing system we are desperately trying to discard, i.e. the logic of a carbon lifeworld, resulting in a fudged-up energy reality that ironically is reduced to a sustainability paradox. This, as the third part explores, has a bearing on its (in)ability to provide a

\footnotetext{
5 There is a range of scholarship engaging with the notion of 'green capitalism'. As Tienhaara (2014) rightly points out there are hundreds if not thousands of varieties of green capitalism floating around, including well-known ones such as Green New Deal (Luke 2009), all overlapping to various degrees. A need for a more nuanced investigation of the discourses and desires reflected in green capitalism is obvious even as many acknowledge that '[f]ully excavating the liberatory and utopian visions coursing through this new "green" spirit of capitalism is a much larger project (Goldstein 2013: 30, 2018). For an outright dismissal of green capitalism and particularly renewables developing within historic capitalist assertions that are now transnationalised and inserted into global patterns of accumulation, see Harris $(2010,2014)$.
} 
transition to a post-carbon reality as it remains embedded in aspirations of efficiency rather than sufficiency, is utility driven instead of infrastructure-focussed and, more importantly, fails to overcome or transform the continued significance of the grid as the conveyor of all energy forms, fossil or non-fossil.

While a large part of the arguments presented here have been built from a range of secondary sources including government policy documents and energy company reports, it is also supported by my own fieldwork where, between 2015 and 2017, I attended several renewables related conferences, industry organized workshops and meets in India, taking notes of the proceedings and interviewing energy producers and related actors at these venues. What is notable is that these events coincided with another ambitious initiative of the Indian Government - Smart Cities Mission (SCM), launched in 2015, and replete with all kinds of vision for the future Indian city. It promises interventions that echo variants of urban sustainability, including specific references to renewable energy such as the creation of a renewable energy cell in all identified smart cities alongside the expectation that 10 per cent of these cities' energy requirements must be met by solar power. In fact, energy constitutes one of the five major development steers within the SCM with renewable energy accounting for 20 per cent of this budgetary allocation (Taraporevala 2018). And yet, even though SCM offers an opportunity to consider how renewables could be actualized in and through the urban, it seems that they do not go beyond gestural notions of making Indian cities 'smart' with little effort to show that smart cities can actively reconfigure energy systems in Indian cities. This is unfortunate, for, as Bulkeley et al (2016) rightly point out, two parallel set of critical enquiries are being forged within urban studies - one around urban energy systems and transitions, and the other on smart cities, as a result of which a chance to explore energy transition processes (and changes to energy systems more generally) as a predominantly urban one is not fully harnessed. What underlines this paper broadly is Rutherford and Coutard's (2014: 1356) call to make 'the inherently co-evolutionary relationship between cities and energy a more central practical and analytical concern', as it explores the role of renewables in recasting the energy question as an urban question, one that requires an almost (impossible) radical shift in the "spatial constitution" of renewable energy (cf. Bridge 2018). 


\title{
A numbers game
}

In April 2018, Indian online news portal thewire.in reported a new record in India's ongoing renewables saga as it crossed the production of 100 billionth unit of renewable energy in a single year, 'a significant accomplishment in very real terms', noting that

\begin{abstract}
India's renewable energy production now stands well ahead of the total electricity generation of relatively populous developing nations like the Philippines, or small but advanced economies like Belgium. It also exceeds all the electricity produced by Israel and Hong Kong combined - where virtually all power comes from burning coal, gas or oil (Worringham 2018).
\end{abstract}

Such press releases conjuring a great felicitous moment are not uncommon, particularly in relation to renewables, but it would do to look deeper into the wheeling of these statistics, instead of accepting these naturalized 'facts' at its face value. For instance, it takes no more than a simple arithmetic to debunk the celebratory milestone of 100 billion units of renewable energy production in a single year when you place it in context against the overall energy production of 1,200 billion units (BU), accounting for only 8 per cent contribution. Despite optimistic scenarios showing renewable energy's contribution to India's electricity generation rising to 20 per cent by 2022, it is yet to break the 10 per cent mark even though this is anticipated by the end of 201921.

\section{Of time and targets}

It is easy to be distracted by the governments' boastful proclamations emphasizing targets and prioritizing a temporal fix that relies on data- and image-bytes through a two-step propaganda of a "power fantasy" (Ghosn 2013: 659). Initially, imaginaries of energy futures are set against apocalyptic predictions such as 'by year so-and-so, we would have run out of coal reserves', or 'by such-and-such year, we would have worked ourselves to extinction', followed by the presentation of an alternative scenario, one that rarely goes beyond slick powerpoints comprising of decontextualized, and delocalised wind turbines and solar panels. These are often peppered with few stock phrases such as the country having the fourth largest installed capacity of wind power or the third largest installed capacity of concentrated solar power in the world. There is little in terms of details in this pamphleteer approach which remains a flashy oneliner promoting a glossy or, in this instance, a green forecast, neither too close to the 
present nor too far into the future, at least 5-10 years away, recalling Harvey's (1990) reminder of the Keynesian maxim that "in the long run we are all dead" but the short run is the only reasonable time horizon over which to operationalize political decisions.

Dominated by this practice of target periodization, renewable energy is marked by scientific epistemologies, taxonomies and measurement regimes (Brace and Geoghegan 2010). To avoid the vulnerability of a debate where its futures are openended, targets emerge, less as a critique of the hegemony of a powerful discursive formation, and more to underscore the distinctiveness of a historical event (Whitington 2016). Uncritically appropriated by politics and oversimplified within policy, these dates are important for the government as it not only shows that it is following international protocol (for example, the globally set targets of IPCC through their frequent 'the clock is ticking' warnings), but is also important for public morale boosting where, by capturing the predicament temporally, it promises a resolution at the end. An illusion of precision masks the uncertainties plaguing the sector to substantiate the effective worthiness of renewable energy even as this temporal imaginary dilutes the discourse to empty posturing. A false sense of security gulls the public into believing that the greater problems of energy supply will be resolved by a certain date. Targets are reassuring as it indicates that the state is working towards something even though there is only a vague sense of what this achievement is going to be.

\section{The lure and lore of installed capacity}

If temporal imaginaries, despite our misgivings, have come to fashion energy policies in a significant manner, it is largely due to the way it has been propped up by a powerful quantitative apparatus, where simple yet effective statistics are used to convey a numeric narrative that is central to the unfolding energy polity. The growing significance of quantification processes using metrics and measurement to map out a cognitive schema for renewables can be noted as energy discourses are single-handedly conducted 'in numbers', leading to concerns of a numeric imperialism subjugating other forms of knowledge. What we are encountering is the rise of a numbers regime based on a mode of valuation that is laden with uncritical assumptions to a point that it lacks common sense. The point here is not to simply question the inordinate trust we have come to place in this algorithmic bravado, but to draw attention to the way key 
debates such as renewables are increasingly embedded in a rigged up 'cultures of calculation' (Appadurai 2012) often to their own detriment.

Metrics and measurements constitute a key calculative tool, as they 'tend to squeeze the complexity of our everyday lives into boxes and databases leaving untold numbers uncounted' (Moats 2016). And yet, metrics thrive on this very premise - to simplify things. Metrics are important in the way they combine proxies, signals, indicators and diverse interpretations and inferences to become powerful instruments, which makes it all the more important to consider what would happen when they are invested with considerable agency (Brockington 2017). In the case of renewables, the metric that is commonly employed is the notion of installed capacity, an energy accounting index that is the favoured yard-stick for policy makers. The idea of installed capacity is quite simple - it assumes one hundred per cent operation with maximum amount of electricity produced every hour of every day over a year. By focusing on the peak rather than the average, installed capacity proves to be an all-important metric prioritising potential, even though this way of forecasting and projecting yields an overoptimistic scenario that is never met. In a context where energy infrastructure is still dominated by the characteristics of fossil fuels and their perception of being always available, renewables struggle to substantiate their reliability against arguments of intermittency, dependent as they are on the vagaries of nature. Thus, a former representative of Suzalon, a prominent renewables producer in India explained, 'installed capacity is a construct, but one easy to quantify especially when renewable energy as a variable phenomenon is not easy to credit as a resource'. This 'power of the single figure, drawing attention to the particular potency of those numerical technologies that can reduce the complexity of experience to a single comparable, quotable, calculable number' (Rose 1991: 680) is quite remarkable when what it offers is a misplaced confidence in an enlarged sense of productive value that in reality is minimal. A few discerning commentators have drawn attention to this obsession with installed capacity as seen in Rosencrasz and Puri's (2017) observation that we need to equally focus on capacity utilization factor which is the real output as compared to the hypothetical assumption of installed capacity. Citing several reports analysing the performance of the renewables sector in India, they draw attention to the fact that the electricity generation capacity of most renewables is rarely above 20 per cent. In fact, 
the Global Energy Statistical Yearbook 2018 shows that the percentage contribution of renewables within India's electricity production has dropped from nearly 25 per cent in 1990 to 16 per cent in 2017, despite a steady increase registered by wind and solar energies. Also, according to the World Development Indicators released by the World Bank, between 2000 and 2015, renewable energy consumption fell in India from 51.6 per cent to 36 per cent. ${ }^{6}$

Thus, the narratives that are often sold in terms of meeting targets fail to provide the complete picture and we are not only left to deal with half-truths but also to puzzle as to why, with all the advancements in energy science, we have been lured into allowing installed capacity to become the global steward of renewables metric. As many energy experts (both in the academic and policy realm) already know, we cannot make different renewable sources commensurable to one another for, one megawatt of wind energy is not equivalent to that of solar or tidal. This aspect of the way we use measures of energy, 'compromised by the high pressure from society for simple answers and straightforward numbers' (Giampetro and Saltelli 2014: 611) has been critiqued by Shove (2017: 3) as they 'reproduce understandings of energy as an allpurpose resource, rather than as something which is generated and consumed in ways that are highly contingent, variable and historically specific'. Confronting us is not just the issue of metric fixation but the delineation of a fictive space for the operation of renewables, setting up a supposed "plane of reality" where we have to settle for a sense of adequacy, not accuracy (Rose 1991: 676). We are confronted with not just a 'juking of stats' (Muller 2018) leading to distortions, but possibly something more sinister where, the bandying of installed capacity as a predominant metric of renewables indicates, to paraphrase Appadurai (2012: 11)

a hazy amalgam of optimization, maximization, choice, quantification, prediction and agonistic individualism. It is the market as imagined in our economics textbooks and lodged in our heads, translated into some sort of individual disposition towards people and resources.

\footnotetext{
${ }^{6}$ https://yearbook.enerdata.net/renewables/renewable-in-electricity-production-share.html; https://data.worldbank.org/indicator/EG.FEC.RNEW.ZS?locations=IN
} 
Installed capacity thus becomes the key modality through which the uncertainty of renewables is transformed into a normative surety via a selective application of probabilities and by opening it up to the practices of speculation.

That India's performative gestures regarding renewables need closer scrutiny becomes evident when we examine more closely its recent plans to increase the deployment of solar technology from 20GW to $100 \mathrm{GW}$ by 2022. As Shidore and Busby (2019: 1183) reveal, such targets emerge through top-down decisions directly from the Prime Minister's office, 'pulled from the air without much study or analysis', and even if any kind of appraisal was involved, the final projections are substantially above the recommendations made. And as they point out, even though the country has increased its installed solar capacity ten-fold from 2.4GW to 196GW between 2014 and 2017, it is still only about 6 per cent of the net generation capacity and 2 per cent of the final electricity consumption. A greater concern is also the fact that a large part of the solar programme continues to rely on solar parks (60 per cent) while rooftop solar struggles to take off with less than 10 per cent of the aspired objective achieved. In a context where land remains critical to the geographies of energy transitions, we need to be careful about prioritizing solar parks which thrive on land-based energy extraction, not any different from the spatial politics of fossil capitalism (Huber and McCarthy 2017). This is where rooftop solar production become important, particularly in the urban context where implementation of energy transitions towards a renewable 'post-carbon economy' is subject to development rules and regulations. Thus, in the Indian city of Chennai, a study by GERMI and Greenpeace (2018) found that the city has a total rooftop solar potential of $1.38 \mathrm{GW}$ (with 42 per cent from residential buildings) but even if the government makes installation of rooftop solars mandatory in all buildings, the Chennai Metropolitan Development Authority (CMDA) will need to make changes under the Tamil Nadu Town and Country Planning Act to ensure that the government order is enacted. According to this report's estimate, all of India's Tier 1 and 2 cities put together can host over $62 \mathrm{GW}$ of rooftop solars. However, assuming an average adoption rate of $10 \%$ over the next 5 years, a total installed capacity of $6 \mathrm{GW}$ is what is actually feasible by 2022 . This low potential was confirmed by a large-scale solar park developer who downplayed the potential of rooftop solars as he was interested in 
accessing a large terrain of productive landscape in a non-urban setting which in the urban context would be impossible:

\footnotetext{
.... if you want to generate all of that within the context of area available in the urban it is going to be very large. You can only do it in rooftops, maybe parking lots but beyond that it doesn't make sense to use land in urban areas which is lot more valuable it doesn't make sense......Either for the wind or solar, the kind of land that is required is not available in urban areas. Rooftop has limited potential. Whereas, once you go outside of cities, exposure to sun or wind is better and land is not a problem.
}

Renewables, in this instance, becomes a problem space as it is brought to reason through the domain of commerce, profit and capital. With the calculative subjectivities of renewables following the derivatives of neo-classical economics, its non-fossil legacy is called into question as it jettisons the larger attributes of sustainability which is already being overturned by the techno-managerial manipulations of market-driven interest groups and sectional lobbies.

\section{Sustainability paradox}

Given the Indian Prime Minister Modi's predilection for sloganeered politics, it is not surprising that a cache of glitzy initiatives has come to signify his rule. A high pitch, for instance, characterizes his renewables agenda where his intention to "home in on surprisingly high returns with the world's largest producer of wind energy' blatantly displays his preference for a corporatist approach. There has been a heady following of this announcement by regional states in India, vying with each other competitively to tap into this 'market' potential. Thus, it came as no surprise when, international travelers passing through Heathrow Terminal 5 in August 2015 encountered an impressive array of banners advertising a Global Investors Meet in the southern Indian state of Tamil Nadu. Held in the regional capital city of Chennai over two days on 9 and 10 September 2015, this lavish affair was meant to showcase the potential of the state as the leading and preferred investment destination for international companies and provide a platform for networking on investment and growth opportunities. Amongst the reasons cited for Tamil Nadu as the ideal investment destination was the proud claim of having the highest capacity renewable energy in India. There was much jiggling of energy scorecards as it was bandied about that Tamil Nadu is the tenth largest in the world in terms of wind power capacity, more than 50 per cent of its total power capacity is from renewable sources, and it is second largest in the country in 
terms of co-gen power plants, all contributing to the State's phenomenal turnaround from a power-deficit to a power-surplus state by $2016-17 .{ }^{7}$ By the end of the Meet, nearly 100 MoUs were signed promising an investment commitment of $\$ 36$ billion with 45 per cent related to proposals in the power sector (35 per cent of which were in the field of solar energy alone). There were high-profile announcements from global energy companies such as SunEdison and Adani Group to invest \$1.8-2.0 billion and \$2.2-3.0 billion respectively in setting up (renewable) energy power projects in the state. Investments were pledged mostly in the setting up of solar and wind parks ranging from large scale (100 MW), which in the case of Adani was an ambitious 650 MW solar park (the largest in the world) to smaller scale set ups of 10-50 MW (to avoid the hassle of land acquisition).

Participants in this meet were mostly private market players in the renewable energy sector ranging from global conglomerates to small-scale entrepreneurs. Concerns around climate change and global warming were shouldered aside, with several participants neatly sidestepping questions on sustainability. As the CEO of an international corporation suggested, somewhat dismissively, 'there will be a separate conference on sustainability where everybody will focus on it but in a platform such as this, it does not get talked about a lot', adding that 'you don't see the overarching theme of sustainability...There is, in fact, a lot more conferences on big projects [which are the ones we target]'.

He acknowledged that when energy-specific programmes are rolled out, there is a fixation with setting targets, a statistical obsession which deters from asking more closely and critically how these targets will be met. To reinforce this point, he explained how, for a private company thinking in terms of large market potential, the focus cannot be so much on this 'overarching theme of sustainability' but on a revenue logic that viewed the 300 million Indians without electricity as a market potential:

If you look at a rural household which spends about $\$ 3$ a month on electricity, this is approximately $\$ 35-40$ a year. There are probably 400 odd million households that fit into this category, actually maybe even 500 million households. Even if they get

7 This needs to be qualified as even though Tamil Nadu emerged as the state with the highest power surplus in the country for 2016-17, a considerable part of it was through commissioning of new power plants (thermal and nuclear), as well as sourcing power from the open, private market. 
electricity, they will continue to spend on energy because electricity from the government is not reliable. So $\mathbf{5 0 0}$ million households times $\mathbf{4 0}$ dollars a year is like 20 billion dollars of energy revenues each year and I think there is a possibility of making 25-30 percent bottomline in that which is $\$ 5$ billion. If you give it a multiple of 15 , you are looking at a business that can generate $\$ 75$ billion of value. There is the question of how can you deliver within those price points. So, this is a sector that is sort of ignored as I don't think there is too much private participation but we believe that we can, with the right business model, deliver the services and make money....because we think we can deliver power and make money from the sector and this is within what they are paying. I am not saying that they have to pay a lot more. They should just spend what they are spending on energy and we will be able to enhance what they are getting today with better services.

His financial model is of course based on the liberal theory of private property ownership and assumes a penchant for material consumption that works well with the middle class but might backfire terribly when it comes to other sections of the society, particularly the poor. The archetype of solar solutions he is seeking to market is informed by a market approach to socio-technological life emphasising privacy and consumption, as he further explained that his ideal testbed would a single-family home where the overall roof area by carpet area is very high, with a better chance of selling a whole package right from solar panels to switches, bulbs and batteries. That renewable energy as a discourse in India subscribes to this bourgeois imaginary is apparent in the logo of the 2016 Renewable Energy Global Investors Meet and Expo (RE-Invest) organised by the Indian Ministry of New and Renewable Energy (an annual feature since 2015) showing a couple of independent homes in a bucolic setting with the standard windmills and solar panels in the background. While et al. (2004: 551) argue that the primary purpose of the urban sustainability fix is to draw "attention to the selective incorporation of ecological [i.e. environmental] goals in the greening of urban governance". They position entrepreneurialism as the prevailing logic of urban governance which is in need of greening. This entrepreneurial logic privileges a vibrant and dynamic private sector as the central actor of urban governance to enhance a city's competitiveness within a globalized economic system and to enable economic growth.

If you discount hydel power, renewable energy is almost entirely produced by private companies in India accounting for 96 percent of the installed capacity. Between 2014 and 2015, with the launch of Modi's renewables programme, almost 300 companies pledged to build $266 \mathrm{GW}$ of renewable energy projects in India by 2022 at 
a cost of over $\$ 100$ billion (Buckley and Sharda 2015). A large majority of them are global corporations from China, Middle East, Western Europe, East and Southeast Asia as well as venture capitalists such as Goldman Sachs exploring the potentials of green capitalism. Some are not from the energy field and are using this opportunity to get a foot into the more attractive infrastructural investment possibilities, while others such as Adani Group might have prior experience as energy developers but their broader commitment to sustainability still remains unsubstantiated. Renewables, for conglomerates such as Adani, are seen as a diversification of their energy portfolio where the company presents itself as India's leading renewable player (4,560 MW) as well as the largest private thermal power producer $(10,440 \mathrm{MW})$ and whose sustainability commitment is conveyed through a corporate social responsibility agenda. This approach is typical of all major private thermal power companies including Adani Power, Tata Power and Reliance Power, all having a significant investment in renewables.

Their programmes reveal a strong finance and policy steer with a focus on the practicalities of setting up a considerable investment in this sector. What they have offered so far is simply a pledge and how far this translates into live projects remains to be seen. This lack of accountability in the state-corporate nexus became obvious when SunEdison, a self-acclaimed largest global renewable energy development company, filed for bankruptcy in April 2016, divesting its global assets to other investors including its operations in India, and defaulting on its public commitment to renewables. While it had promised to invest $\$ 15$ billion over the next 5 to 7 years with an ambitious target of $15.2 \mathrm{GW}$ of renewable energy capacity, it had only $438 \mathrm{MW}$ operating on ground with another $800 \mathrm{MW}$ in the pipeline, having concentrated on mergers and acquisitions and aggressively bidding in state auctions at lowest possible prices. Sustainability's high concerns are shunted aside by an economic determinism where everyone's doing it for a nickel with the objective of extracting as much as possible from the relationship between a productive landscape and their potential markets. It is thus difficult to articulate a meaningful discourse of sustainability as they continue to rest on values and judgements that is not much different from that of a carbon rationale. The fear instead is that renewables are reduced to a Latourian sense of a quasi-object or what Swyngedouw (2006) refers to as a socio-natural hybrid where 
capitalist life can prevail. There is a tell-tale sign of a sustainability paradox where perverse outcomes raise questions about the ability of renewables to master a transition to a post-fossil performativity for, as Rutherford and Coutard (2014: 1354) remind us, 'not all radical change in patterns of provision or use of energy consists in, or spontaneously aligns with, a deliberate and managed transformation towards a "more sustainable" configuration, however defined'.

\section{Transitions, really?}

Despite much stock being placed on renewables to facilitate a regime shift towards an ecologically more sustainable set of registers (described often through the notion of low- or zero-carbon), the idea of such a straightforward transition is increasingly seen as unrealistic, forcing a difficult confrontation with renewables and its implications for a clean energy future. This disillusionment with renewables and its promise of an energy transition comes amidst a growing suspicion that it may not be so different from fossil fuel philosophy given the orthodoxy of the material networks underpinning its configuration and production. Thus, even though the political project of renewables challenges the geo-institutionally established structure of carbon economy, the way its energy practice is inserted rigidly within an existing carbon-oriented system has led some scholars such as Raman (2013) to declare that renewable energy technologies are indeed being fossilized. Caught between the aspirations of a post-carbon utopia and the persistent reality of carbon structures, renewables fall into a kind of paradigmatic limbo, resulting in a paradoxical condition where it can be defined neither as distinct from nor in relation to carbon economy. As Glover (2006) suggests, it is somewhere in the transition that the social promise for renewable energy starts to go badly wrong. This notion of transition also holds renewable energy to ransom, not only through a state-brokered corporatisation of its production, but also by compelling it to follow the economies of scale of conventional energy infrastructure. Given this awkward dialectical position between renewables and fossil fuels, any characterization of a functionalist, linear transition from carbon to a post-carbon society comes across as disjointed and an ultimately compromised instance of a counter-carbon project.

This becomes an even greater challenge when you try to make energy transitions work through urban processes, practices and change as decarbonizing the urban 
proves to be a not so straightforward proposition, entailing much more than a mere shift in energy sources, with significant implications for not only challenging contemporary modes of urbanization but how 'the urban' itself is constituted. What is needed here is not a transition (of energy systems) in cities but a transition of cities (and its energy systems) (Huang et al 2018). The issue is also that there is not a singular notion of urban energy transition which is broadly defined as a radical, systemic and managed change towards more sustainable patterns of energy provision and use, but is diverse, non-linear and at times conflicted, a plurality that is at best only partially captured by talk of "the energy transition". Following Luque-Ayala's (2018) advancement of novel ways of thinking about the decarbonization-development interface and echoing his notion of a post-development carbon, could we provocatively consider a 'post-urban carbon' instead of our current preoccupation with post-carbon cities thus opening up a space for multiple and possibly more vernacular interpretations of urban energy transitions? This 'post-urban carbon' seeks to interrogate not just the possibility of energy transitions but alternatives to urbanization, tackling head on some obvious internal contradictions embedded in low carbon interventions such as the fundamental antimonies of utilities and infrastructure or efficiency versus sufficiency argument.

\section{Utilities/Infrastructure}

For a long time, the notion of supplying key services essential to living in a modern lifeworld such as water, sewage, electricity, telecommunications and transportation was firmly embedded in the idea of a public utility, crucially framing our understanding of infrastructure in the twentieth century. While privatization of these 'public goods' over the past few decades has changed the way we perceive utilities as infrastructure, what needs to be noted is the subtle binary that emerged between utilities and infrastructure where products such as pipes, ducts, wires, conduits, electric transmissions, pylons, tunnels (and now servers) compose the sheer physicality of utility networks (Graham and Marvin 1995) as against the nuanced materiality of infrastructure's processual flows, circulations and metabolisms (Swyngedouw 2006). Scholars picking up on this import tend to give greater credence to the material turn where the question of materiality far exceeds any invocation of physicality (Anderson and Wylie 2009), while, as private market players, renewable energy developers tend 
to prioritise utility which, for them, is an axiom for operational stability, service continuity and technical normality (Luke 2010). In the context of energy utility, where privatization has entailed a convoluted disentangling of generation, transmission and distribution, renewables producers tend to avoid the disarray of infrastructural challenges, turning instead to a socio-technological reimagination emphasizing energy as an artefact and mechanical system. But in positioning themselves as service providers, there is an attempt to enforce a simple production-consumption nexus, pressing the case of energy as a utility demand, one that bypasses infrastructural concern. While at an elementary level this might seem like a neoliberal invocation of energy as commodity, there is something more to be said here about this emphasis on product-based solutions such as batteries, heaters and unitary systems which can be easily conveyed directly to end users or consumers.

As economic analysts have found, energy transition in this context, by avoiding an infrastructural approach, poses a strategic challenge for utilities as well, especially around the question of value capture, generated as it is by a varied range of actors from profit-driven private companies to individual homeowners as well as non-profit organisations or quasi-public entities, many of them operating at the limits of what we would usually understand as a market. Renewables raise compelling questions about the relationship between utilities and infrastructure, both becoming collectively problematic where it is difficult to frame infrastructure as a good or a utility, while at the same time, utility retains, under transformative conditions, a somewhat material connection with infrastructure, one that is not entirely explained by the conventional understandings of commodities, economies and markets. The challenge is also in the integration and diffusion of a dynamic and fluid utility-scale renewables into a more inert and fixed networked infrastructure that is firmly entrenched in the urban. There is a scalar aspect which gains traction where a visible evocation of renewable utilities as small energy technologies (from photovoltaics to meters) prove to be confined experimental explorations that struggle to produce extended spatial imaginaries of a much larger, networked infrastructure regime involving generation and transmission, subverting infrastructure's role as a powerful instrument in energy transitions. This is evident in India's Smart Cities Mission (SCM) where smaller area-based developments and pan-city (infrastructural) solutions have been emphasized in the initial government 
issued guidelines but, in terms of actual allocation, over 80 per cent of the SCM budget has gone towards the former (which is little over 7 per cent of the area of the 99 smart cities) (Taraporevala 2018). Most of the pan-city proposals are about networked interventions such as centralised command and control centres rather than actually revamping existing urban infrastructure. They are less about managing a crumbling electricity network with a preference for device-based solutions such as smart cards and pods that do little to dislodge the carbon logic in cities. More importantly, efforts of renewable utilities to effect a socio-technical change between energy, cities, their actors and users is not fully realized as it continues to be based on a demand versus supply mandate, one that incentivises efficiency over sufficiency.

\section{Efficiency/Sufficiency}

An enduring feature of the argument for a sustainable way of life is its perverse characterization by two contrary principles - efficiency and sufficiency. Towards the end of the nineteenth century, efficiency emerged as the dominant institutional principle of resource use based on the optimization of input-output or more precisely of a cost-benefit ratio (Spengler 2018) despite misgivings that delivering the same or more for less energy neither discourages energy-intensive ways of life nor promotes an alternative that is compatible with drastic carbon reduction (known famously as the Jevons Paradox). Privileged by a utilitarian, market-driven criteria, this trope of ecological modernization continues to be favoured by global think tanks such as the International Energy Association (IEA), even as energy scholars are building a consistent critique of efficiency around the fact that its institutional trappings are shaped, not by the imperatives of "sustainability," but by the requirements of regulated utilities and the application of technical lenses' (Lutzenhiser 2014: 148-9). As a problematic paradigm based on a 'hard' physical-technical-economic model (ibid.) requiring a change only in the techniques of the natural sciences and demanding little or nothing in the way of change in human life (Hardin 1968 cited in Spengler 2018), Princen $(2003,2005)$ has provided the most provocative challenge to its "normative neutrality" through the logic of sufficiency, pitching it as a contrasting practice resonant with long-term sustainable resource use. Those following the above argument are convinced that a clear socio-technical energy transition can happen only through the socio-material organization of sufficiency and not the performative calculus of 
efficiency. However, Spengler (2016) is cautious about playing off one against the other for, even if one cannot doubt the principle of sufficiency to steer ecologically sensitive patterns of use, concerns remain over its formulation of "enoughness" or "too muchness" (Princen 2005), where human beings are expected to limit their consumption to below a level that would be "too much" in terms of emissions and resource extraction. This idea of sufficiency as maximum is problematic as it does not favour the elimination of inequality, nor does it regard benefitting the less well off as generally more important than rewarding the better off (Casal 2007).

The moral argument that it is not about everyone having the same but having enough to maximise the incidence of sufficiency would of course have countries in the global South crying foul. Spengler (2016) offers a corrective by suggesting two different types of thresholds for sufficiency, a minimum and a maximum, where the former places importance on everyone having at least enough, one that is tied to the principle of equality. It is this idea of sufficiency that countries such as India emphasise when they reason around energy poverty and energy justice. This takes a greater significance in the urban condition whose uneven development poses a challenge for distributive energy justice. While sufficiency based on a minimum threshold might conform to the demands of equality and priority, the extent to which it supports the core of the sustainability idea is suspect as acknowledged by renewable energy producers in India for whom sufficiency revolves not only around some having less than others (heightened as a North/South divide) but also the fact that they have too little and could do with more, an argument for increased consumption, if any. However, as the head of a leading multinational energy company investing in India's renewables market observed, even though there is an emphasis on sufficiency (not falling below a critical threshold of advantage), there is equally some anxiety about its ramification on efficiency:

...it is much easier to measure a generation project because there is a meter and you can monitor electricity, and thereby it is easier to finance it. There is a tariff for electricity, right? Whereas for efficiency improvements there is no mechanism in the metre. You cannot say that you are saving $X$ and there is a metre and there is a contract and you can write around that as a result. It is always challenging to finance such projects...It is much easier to finance energy generation projects in renewables 
[based on sufficiency] than it is to finance energy saving projects [to improve efficiency]. ${ }^{8}$

$\mathrm{He}$ is not entirely right in this argument for this kind of justification is often made by private renewables developers to gain incentives and subsidies from the state. What he is asking for is a better mechanism of exchange between the technical-material and socio-political domains of energy efficiency. He is wrong is in his assumption that there is no formal way of accounting for it through standards and classifications. Recent trends to certify buildings or systems (such as LEED certification) are a way of 'blackboxing' energy uncertainty, bringing them into a technologically articulated realm of certainty through a rigid procedure of calculation and identification. Nevertheless there is a genuine difficulty in sustaining principles of sustainability in the eyes of developers and energy utilities within the emerging renewables mandate where, despite their contrariness, a both/and rather than an either/or notion of sufficiency and efficiency gets entangled in a not easily comprehensible relation, posing a conundrum to each other and undermining their respective rationale.

\section{Grid-locked}

One of the reasons why the efficiency vs sufficiency argument gets so easily muddled in the context of renewables is the lack of clarity that renewables producers have in terms of the geographies of such an energy regime. Renewables narratives are distinctly and deliberately aspatial despite repeated calls to rethink them in spatiallyconstituted terms. This is mainly because of the sustained presence of the grid as an energy imaginary even as it encapsulates all the contradictions and paradoxes outlined in the previous two sections - between utilities and infrastructure or efficiency and sufficiency. It is a key means of keeping utility-scale functions running reasonably intact within an increasingly unreliable infrastructure network, especially in the urban condition, while sustaining the notion of efficiency through an assuredly sufficient resource generation and distribution system. Everyday interactions with the grid however tend to be conducted in topological terms where a single, wide area synchronous grid is seen as a neutral, technical landscape drawing electricity from its

\footnotetext{
$8 \mathrm{It}$ is interesting to note that he ignored the emerging but yet to establish role of parallel market-oriented institutions such Energy Service Company (ESCO) or Energy Efficiency Service Limited (EESL) financed through the banking sector to promote a certified approach to energy efficiency.
} 
point of generation and distributing it through a network of transmission lines, substations and transformers to homes and businesses. There is a lesser tendency to perceive the grid as a volatile mix of actants comprising 'coal, sweat, electromagnetic fields, computer programs, electron streams, profit motives, heat, lifestyles, nuclear fuel, plastic, fantasies of mastery, static, legislation, water, economic theory, wire and wood' (Bennett 2005: 48). This is an approach pursued by Luque-Ayala and Silver (2017) in their conceptualisation of the urban through the grid where they view the grid as a critical political site for mediating urban life whilst opening up new possibilities expressing dissent and advancing social justice, democratic service delivery and urban autonomy.

Unfortunately for the prospects of energy transitions, both renewables and smart cities tend to reinforce the grid not through the (disruptive) material politics of urban infrastructure but as an intangible spatio-technological logic that does little to dislodge the existing carbon rationale. The urban, conversely, is rendered abstract, becoming an object of improvement known, delimited, calculated and understood through the grid (Bulkeley et al 2016). This is also why the pursuit of the idea of a post-urban carbon rather than the common calls for a post-carbon urban makes better sense. The notion of the post-urban is invoked here not in a Koolhaas's sense of the stylistic sensational or an apocalyptic end of urbanism per se where it is judged against some infinitely superior idealised version of the urban. Instead, 'post' is employed to emphasise further probing of our conceptualisations of the urban, one that departs from that of the post-carbon urban which remains rooted in a methodological cityism (Angelo and Wachsmuth 2014). In acknowledging the extended dimensions of contemporary urbanisation encapsulating the urban as well as the non-urban, the post-urban carries a distinct analytical potential as an avenue through which the idea of transitions could be imagined and practised, one that is detached from any kind of carbon initiative, low, zero or whatever.

\section{Reflections}

At a recent Renewable Energy and Sustainable Environment (RESE 2017) conference in southern India, the managing director of Swelect Energy Systems Limited, an upcoming solar energy producer, delivered his plenary address where he discussed 
his company's sojourn from the conventional power sector to the potential of renewable energy, with an aim of increasing their generation capacity to $1 \mathrm{GW}$ by 2020 . As a market-oriented entity, his company, like many others, is rooted in the instrumental rationality of a profit-oriented capitalism focussing more on financial tangibles such as cost vs performance, investments and returns, value for money, and other such operational aspects. Highlighting the competitive bidding process for the production of renewable energy in India involving a tariff-based reverse auction where the lowest price tender is generally selected, he talked about the pressures his company faced in delivering energy at very low unit prices (which are being recklessly undercut with little room for absorbing cost overruns), voicing concerns of punitive action from the state if they fail to comply with any part of the agreement. While there has been no evidence so far of the government successfully pursuing any of the defaulters (and there are several), he nevertheless used this point to make an impassioned plea to an audience of mostly young engineering students: 'if we are to succeed in this business, then you must consume more [electricity]'. This is a classic utilitarian argument based on the principle of efficiency which, when combined with the persistent state logic of energy sufficiency, leads to a veritable sustainability paradox, as a result of which renewable energy initiatives remain, in real terms, little more than a 'socioecological fix' to sustained capital accumulation (McCarthy 2015).

Thus, amongst several sustainable development programmes launched by the Indian government, including the much-hyped Smart Cities Mission, there is only a perfunctory nod to renewables as an experimental space demonstrating an alternative energy future (cf. McLean et al. 2016; Evans et al. 2016). In the case of Smart Cities Mission, the onus is on a range of mechanistic interventions ranging from meters to grids and networks, with those participating in this programme remaining unclear about their energy strategy. In a context where Indian metropolises tend to have a disproportionate claim on their state's electricity generation, (a city like Chennai consumes more than 20 per cent of Tamil Nadu's total electricity production and only a paltry 5 per cent comes from renewable sources), a chance for a concrete incorporation of renewables to radically reshape India's ecologies and resources is more than a missed opportunity. Instead, what is proposed is a series of ineffectual steps that might seem impressive but aren't. This includes proposals by the City 
Corporation to replace all street lighting with LED bulbs, demonstrating their valorisation of energy efficiency. Chennai's smart city agenda promising 10 per cent of renewables in its energy mix suggests a doubling of the existing contribution but remains woefully lower than the national target of increasingly its share of renewables to 20 per cent. This premise equally does not indicate a major reconfiguration of the socio-material challenges of its infrastructural networks but emphasises instead a utility oriented technological fetish, allowing little room for an energy transition in any meaningful sense.

This paper is set in this backdrop of missed opportunities, raising difficult questions about the prospects of renewables in India establishing a new energy paradigm. A hobbyhorse in contemporary energy politics, renewables have gained political consciousness to an extent that it is mined judiciously, firstly by policymakers, followed by an enthusiastic horde of mostly private producers. This spectacular rise notwithstanding, we are sorely lacking a discerning body of knowledge to investigate renewables beyond what we already have - a very loose understanding of an energy alternative that is susceptible to quick change but offers little robust evidence of a paradigmatic shift. Heeding to recent calls for a broader energy science, involving a richer interplay to 'reframe' a new epistemic system (Castree and Waitt 2017), this paper begins by interrogating renewables' cognitive schema deploying a deliberate 'science of numbers' to portray an exaggerated sense of its energy reality. There is a self-assured confidence in its calculative ethos whose metrics and measures conjure a statistical significance, leading to an obsessive temporal fix. This constrains renewables to a rhetoric of crude determinism that suggests that we might be closer to the goals of sustainability than we actually are. It is not only this rigging of half-truths that causes discomfort over an idiosyncratic entextualization of numbers (Guyer et al. 2010), but also the fact that it jeopardises a majority of sustainability concerns through the exasperation of its intrinsic contradictions, internalized as it is by a prevailing carbon logic. As renewables continue to be embedded in an orthodox institutional structure endorsing a capitalist way of life, the persistence of renewables in facilitating a linear energy transition becomes unviable. There is a perversity to its 'sustainability conversation' (Angelo and Wachsmuth forthcoming) where a mutually constitutive paradox characterising historically contingent antinomies, such as efficiency and 
sufficiency or utilities and infrastructure, is troubled and distorted. The transformative potential of renewables to generate a 'post-urban carbon' is undercut by a loose sort of referencing to parallel initiatives such as the Smart Cities Mission as a result of which an opportunity to actualizing renewables through the urban is lost. Instead they remain tied to a conventional understanding of a grid that is underwritten by an established carbon rationale that makes impossible for renewables to forge new kinds of energy imaginaries.

\section{References}

Anderson, Ben, \& Wylie, John. (2009). On Geography and Materiality. Environment and Planning A: Economy and Space, 41(2), 318-335.

Angelo, Hillary, \& Wachsmuth, David. (2015). Urbanizing urban political ecology: A critique of methodological cityism. International Journal of Urban and Regional Research, 39(1), 16-27.

Appadurai, Arjun. (2012). The Spirit of Calculation. The Cambridge Journal of Anthropology, 30(1), 3-17.

Brace, C, \& Geoghegan, H. (2010). Human geographies of climate change: Landscape, temporality, and lay knowledges. Progress in Human Geography, 35(3), 284-302.

Bridge, Gavin. (2018). The map is not the territory: A sympathetic critique of energy research's spatial turn. Energy Research \& Social Science, 36(February), 11-20.

Brockington, Dan. (2017). Measurements and Metrics: Introduction. Environment and Society: Advances in Research, 8, 1-7. 
Buckley, T, \& Sharda, J. (2015). India's electricity-sector transformation: Global capacity building. Cleveland $\mathrm{OH}$ : Institute for Energy Economics and Financial Analysis.

Bulkeley, Harriet, McGuirk, Pauline M, \& Dowling, Robyn. (2016). Making a smart city for the smart grid? The urban material politics of actualising smart electricity networks. Environment and Planning A, 48(9), 1709-1726.

Casal, Paula. (2007). Why Sufficiency is Not Enough. Ethics, 117(2), 296-326.

Castree, Noel, \& Waitt, Gordon. (2017). What kind of socio-technical research for what sort of influence on energy policy? Energy Research \& Social Science, 26, 87-90.

Chatterjee, Elizabeth. (2017). Reinventing state capitalism in India: A view from the energy sector. Contemporary South Asia, 25(1), 85-100.

Dubash, Navroz K, Khosla, Radhika, Rao, Narasimha D, \& Bhardwaj, Ankit. (2018). India's energy and emissions future: an interpretive analysis of model scenarios. Envrionmental Research Letters, 13(8), 1-11.

Evans, James, Karvonen, Andrew, \& Raven, Rob (Eds.). (2016). The Experimental City. London and New York: Routledge.

Ghosn, Rania. (2013). Roadmap 2050 and the promised landscapes of low carbon. Paper presented at the 101st ACSA Annual Meeting Proceedings, New Constellations, New Ecologies, San Francisco.

Giampietro, Mario, \& Saltelli, Andrea. (2014). Footprints to nowhere. Ecological Indicators, 46(November), 610-621.

Glover, L. (2006). From love-ins to logos: Charting the demise of renewable energy as a social movement. In J. Byrne, N. Toly \& L. Glover (Eds.), Transforming power: 
Energy, environment and society in conflict (pp. 249-270). New Brunswick NJ: Transaction Publishers.

Goldstein, Jesse. (2013). Appropriate technocracies? Green capitalist discourses and post capitalist desires. Capitalism Nature Socialism, 24(1), 26-34.

Goldstein, Jesse. (2018). Planetary improvement: Cleantech entrepreneurship and the contradictions of green capitalism Cambridge MA: The MIT Press.

Graham, Stephen, \& Marvin, Simon. (1995). More than ducts and wires: Post-fordism, cities and utility networks. In P. Healey, S. Davoudi, S. Graham \& A. Madanipour (Eds.), Managing cities: The new urban context. London: Wiley.

Gujarat Energy Research and Management Institute, \& Greenpeace. (2018). Rooftop revolution: Unleashing Chennai's solar potential: GERMI and Greenpeace.

Guyer, Jane I, Khan, Naveeda, Obarrio, Juan, Bledsoe, Caroline, Chu, Julie, Diagne, Souleymane Bachir, . . . Verran, Helen. (2010). Introduction: Number as Inventive Frontier. Anthropological Theory, 10(1-2), 36-61.

Harris, Jerry. (2010). Going green to stay in the black: Transnational capitalism and renewable energy. Race \& Class, 52(2), 62-78.

Harris, Jerry. (2013). Can green capitalism build a sustainable society? International Critical Thought, 3(4), 468-479.

Harrison, Conor, \& Popke, E Jeffrey. (2017). Critical energy geographies. In B. D. Solomon \& K. E. Calvert (Eds.), Handbook on the geographies of energy (pp. 490501). Cheltenham UK and MA USA: Edward Elgar Publishing Limited.

Hart, Keith. (2010). Models of statistical distribution. Anthropological Theory, 10(1-2), 67-74. 
Hart, Keith. (2012). A Note on Arjun Appadurai's 'The Spirit of Calculation'. The Cambridge Journal of Anthropology, 30(1), 18-24.

Harvey, David. (1990). Between space and time: Reflections on the geographical imagination. Annals of the Association of American Geographers, 80(3), 418-434.

Huang, Ping, Broto, Vanessa Castán, \& Liu, Ying. (2018). From "transitions in cities" to "transitions of cities": The diffusion and adoption of solar hot water systems in urban China. Energy Research \& Social Science, 36(February), 156-164.

Huber, Matthew T, \& McCarthy, James. (2017). Beyond the subterranean energy regime? Fuel, land use and the production of space. Transactions of the Institute of British Geographers, 42(4), 655-668.

Isaksen, Kari-Anne, \& Stokke, Kristian. (2014). Changing climate discourse and politics in India. Climate change as challenge and opportunity for diplomacy and development. Geoforum, 57(November), 110-119.

Jasanoff, Sheila. (1993). India at the crossroads in global environmental policy. Global Environmental Change, 3(1), 32-52.

Lahiri-Dutt, Kuntala. (2016). The diverse worlds of coal in India: Energising the nation, energising livelihoods. Energy Policy, 99(December), 203-213.

Latour, Bruno. (2004). Why Has Critique Run out of Steam? From Matters of Fact to Matters of Concern. Critical Inquiry, 30(Winter), 225-248.

Luke, Timothy W. (2009). A green new deal: Why green, how new, and what is the deal? Critical Policy Studies, 3(1), 14-28.

Luke, Timothy W. (2010). Power Loss or Blackout: The Electricity Network Collapse of August 2003 in North America. In S. Graham (Ed.), Disrupted Cities: When Infrastructure Fails (pp. 55-68). New York and London: Routledge. 
Luque-Ayala, Andrés. (2018). Post-development carbon. In A. Luque-Ayala, S. Marvin \& H. Bulkeley (Eds.), Rethinking urban transitions: Politics in the low carbon city (pp. 224-240). London and New York: Routledge.

Luque-Ayala, Andrés, \& Silver, Jonathan (Eds.). (2016). Energy, power and protest on the urban grid: Geographies of the electric city. London and New York: Routledge.

Lutzenhiser, Loren. (2014). Through the energy efficiency looking glass. Energy Research \& Social Science, 1(March), 141-151.

McCarthy, James. (2015). A socioecological fix to capitalist crisis and climate change? The possibilities and limits of renewable energy. Environment and Plannign A: Economy and Space, 47(12), 2485-2502.

McCarthy, James, \& Thatcher, Jim. (2017). Visualizing new political ecologies: A critical data studies analysis of the World Bank's renewable energy resource mapping initiative. Geoforum, Online.

McEwan, Cheryl. (2017). Spatial processes and politics of renewable energy transition: Land, zones and frictions in South Africa. Political Geography, 56(January), 1-12.

McLean, Anthony, Bulkeley, Harriet, \& Crang, Mike. (2016). Negotiating the urban smart grid: Socio-technical experimentation in the city of Austin. Urban Studies, 53(15), 3246-3263.

Moats, David. (2016). Of Stories and Numbers: Rethinking the Settlement between Anthropology and Metrics in Global Health. Science as Culture, 25(4), 594-599.

Muller, Jerry Z. (2018). The Tyranny of Metrics. Princeton Princeton University Press.

Princen, Thomas. (2003). Principles for Sustainability: From Cooperation and Efficiency to Sufficiency. Global Environmental Politics, 3(1), 33-50. 
Princen, Thomas. (2005). The Logic of Sufficiency. Cambridge MA and London: The MIT Press.

Raman, Sujatha. (2013). Fossilizing Renewable Energies. Science as Culture, 22(2), 172-180.

Robbins, Paul, \& Moore, Sarah A. (2013). Ecological anxiety disorder: diagnosing the politics of the Anthropocene. Cultural Geographies, 20(1), 3-19.

Rose, Nikolas. (1991). Governing by numbers: Figuring out democracy. Accounting, Organizations and Society, 16(7), 673-692.

Rosencranz, Armin, \& Puri, Kamakshi. (2017). Why Increasing India's Solar Energy Capacity Won't Work.

Rutherford, Jonathan, \& Coutard, Olivier. (2014). Urban energy transitions: Places, processes and politics of socio-technical change. Urban Studies, 51(7), 1353-1377.

Shidore, Sarang, \& Busby, Joshua W. (2019). What explains India's embrace of Solar? State-led energy transition in a developmental polity. Energy Policy, 129(June), 11791189

Shove, Elizabeth. (2017). What is wrong with energy efficiency? Building Research \& Information, 1-11.

Spengler, Laura. (2016). Two types of 'enough': sufficiency as minimum and maximum. Environmental Politics, 25(5), 921-940.

Spengler, Laura. (2018). Sufficiency as Policy: Necessity, Possibilities and Limitations. Baden-Baden: Nomos Verlasgesellschaft. 
Swain, A K, \& Sharma, I. (2016). Are the government's renewable energy targets realistic?, thewire.in.

Swyngedouw, Erik. (2006). Circulations and metabolisms: (Hybrid) Natures and (Cyborg) Cities. Science as Culture, 15(2), 105-121.

Taraporevala, Persis. (2018). Demystifying the Indian smart city: An empirical reading of The Smart Cities Mission (pp. 1-35). New Delhi: Centre for Policy Research.

Tienhaara, Kyla. (2014). Varieties of green capitalism: Economy and environment in the wake of the global financial crisis. Environmental Politics, 23(2), 187-204.

Whitington, J. (2016). What does climate change demand of anthropology? PoLAR: Political and Legal Anthropology Review, 39(1), 7-15.

Worringham, Charles. (2018). Record Set as India Produces 100 Billionth Unit of Renewable Energy in a Year, The Wire.

Yenneti, Komali, Day, Rosie, \& Golubchikov, Oleg. (2016). Spatial justice and the land politics of renewables: Dispossessing vulnerable communities through solar energy mega-projects. Geoforum, 76(November), 90-99. 